П.Г. Берднік ${ }^{1}$ Ю.С. Шапран ${ }^{2}$

${ }^{1}$ Харківський національний університет ім. В.Н. Каразіна, Харків

${ }^{2}$ Державний університет інфраструктури та технологій, Київ

\title{
ІМІТАЦІЙНА МОДЕЛЬ ВПЛИВУ ТОЧНОСТІ ОЦІНКИ КОЕФІЦІЄНТУ ГОТОВНОСТІ МОБІЛЬНИХ КОНТРОЛЬНО-ДІАГНОСТИЧНИХ СИСТЕМ НА ДОСТОВІРНІСТЬ КОНТРОЛЮ АПАРАТУРИ РАДІОНАВІГАЦІЇ МОРСЬКОГО ТРАНСПОРТУ
}

У статті показаний вплив технічного стану апаратури радіонавігації морського транспорту на часові та економічні показники морських перевезень. Запропонований метод побудови імітаційної моделі, який полягає у врахуванні ймовірностей знаходження мобільних контрольно-діагностичних систем і апаратури радіонавігації у відповідних станах експлуатації-справному або несправному. Розроблені аналітичні співвідночення для визначення ймовірності знаходження апаратури радіонавігацї у відповідних станах експлуатації. Запропонована імітаційна модель, яка заснована на особливостях параметрів контролю апаратури радіонавігації та похибок мобільної контрольно-діагностичної системи, шзо застосовується при контролі.

Ключові слова: імітаційна модель, контроль, технічний стан, апаратура радіонавігації, морський транспорт.

\section{Вступ}

Актуальність проблеми. Апаратура радіонавігації використовується для керування морським транспортом (суднами) за допомогою радіотехнічних приборів. Основні задачі, які вирішує радіонавігація: визначення координати судна та його місце розташування щодо інших точок, направлення виходу в заданий район. Вирішують ці питання за допомогою наступної апаратури радіонавігації: радіокомпасів, радіомаяків, радіонавігаційної системи. При цьому радіомаяк передає точні координати, працює самостійно або відноситься до радіонавігаційної системи. Тобто всі дані передаються, як правило, через супутник, i за допомогою радіокомпасу можна отримати точні дані про місце розташування судна.

Для обчислення дійсного напрямку руху та швидкості морського транспорту підраховують геометричну суму векторів: курс та швидкість, відносно води (за допомогою двигуна); напрям і сила (швидкість дрейфу); напрям і швидкість течії.

Для того щоб морський транспорт привести із одного місця в інше необхідно визначити генеральний напрям, за яким слід буде вести цей транспорт. Це $\epsilon$ попередньою прокладкою курсу. Після того, як судно буде рухатися за курсом, тоді проводять контроль місця його положення за допомогою апаратури радіонавігації. Слід відмітити, що помилки при визначенні місця положення морського транспорту можуть суттєво вплинути як на швидкість переміщення (проходження строго за прокладеним курсом або проходження додаткової відстані за рахунок внесення похибки у цей курс), так і на матеріальні витрати (паливо, витрати на додатковий час перебу- вання на маршруті). Отже, від достовірності контролю апаратури радіонавігації морського транспорту залежить оперативність і економічність морських перевезень. При цьому достовірності контролю апаратури радіонавігації залежить від справності засобів контролю - мобільних контрольно-діагностичних систем [1 - 3].

Таким чином, оцінка впливу точності оцінки коефіцієнту готовності мобільних контрольнодіагностичних систем на достовірність контролю технічного стану апаратури радіонавігації морського транспорту $\epsilon$ актуальною науковою задачею. Для розв'язання цієї задачі розроблена відповідна імітаційна модель.

Аналіз літератури. Підтримка високого рівня справності морського транспорту можлива лише шляхом підвищення ефективності експлуатації мобільних контрольно-діагностичних систем, тобто підвищення коефіцієнту готовності [4 - 8].

Для підвищення ефективності контролю апаратури радіонавігації морського транспорту необхідно оцінити якість (достовірність, точність) оцінки коефіцієнту готовності мобільних контрольно-діагностичних систем. При цьому рішення завдання оцінки технічного стану для апаратури радіонавігації експериментальними і статистичними методами, у силу часових обмежень, надто складне [8]. Тому оцінку коефіцієнту готовності мобільних контрольно-діагностичних систем як для існуючих, так і для перспективних зразків, пропонується здійснити за допомогою математичного моделювання процесів вимірювального контролю апаратури радіонавігації та мобільних контрольно-діагностичних систем, що застосовуються при контролі цієї апаратури $[1,2]$. 
Недоліками існуючих моделей вимірювального контролю складних зразків $є$ те, що враховується лише вплив повноти і глибини контролю на достовірність контролю і не враховується якість обслуговування самих засобів контролю, які використовуються при цьому $[3,4,7]$.

Пропонується імітаційна модель вимірювального контролю апаратура радіонавігації позбавлена цього недоліку, що забезпечить досягнення необхідного розрахункового рівня проходження морського транспорту строго за прокладеним курсом 3 меншими матеріально-технічними витратами.

Метою статті $\epsilon$ розробка імітаційної моделі впливу точності оцінки коефіцієнту готовності мобільних контрольно-діагностичних систем на достовірність контролю технічного стану апаратури радіонавігації морського транспорту.

\section{Основна частина}

Для побудови імітаційної моделі пропонується використати метод, зміст якого полягає у тому, що оцінка контролю апаратури радіонавігації морського транспорту описується формулою:

$$
\mathrm{P}_{\mathrm{i}, \mathrm{j}}=\mathrm{P}_{\mathrm{i}}^{\mathrm{O}} \sum_{\boldsymbol{l}=1}^{\mathrm{k}} \mathrm{P}_{\boldsymbol{l}}^{\mathrm{c}} \mathrm{P}_{\mathrm{j}, \mathrm{i}, \boldsymbol{l}},
$$

де $\mathrm{k}$ - число станів мобільних контрольно-діагностичних систем, призначених для контролю апаратура радіонавігації;

$\mathrm{P}_{\mathrm{i}}^{\mathrm{O}}$ - апріорна ймовірність знаходження апаратури радіонавігації в і-м стані;

i i j - стан апаратури радіонавігації (i=1 - працездатна; i =2 - непрацездатна) і визначений стан апаратури радіонавігації за результатами контролю (j=1 - придатна до подальшої експлуатації; j=2 непридатна до подальшої експлуатації);

$l$ - стан мобільних контрольно-діагностичних систем, що застосовується для контролю апаратури радіонавігації;

$\mathrm{P}_{l}^{\mathrm{c}}$ - апріорна ймовірність знаходження мобільних контрольно-діагностичних систем в $l$-му стані;

$\mathrm{P}_{\mathrm{j}, \mathrm{i}, \boldsymbol{l}}$ - умовна ймовірність того, що в результаті контролю апаратура радіонавігації знаходиться у стані j, при умові,що вона знаходиться у стані i, a мобільна контрольно-діагностична система - у стані $l$.

Відповідно до формули (1) достовірність контролю апаратури радіонавігації дорівнює

$$
\mathrm{D}=\mathrm{P}_{1,1}+\mathrm{P}_{2,2}=1-\left(\mathrm{P}_{1,2}+\mathrm{P}_{2,1}\right),
$$

а статистичний коефіцієнт готовності зразка мобільної контрольно-діагностичної системи дорівнює $\mathrm{P}_{1,1}$.
Коефіцієнт готовності мобільних контрольнодіагностичних систем до застосування визначається так:

$$
\mathrm{K}_{\Gamma}=\frac{\mathrm{P}_{1}}{\sum_{\mathrm{i}=1}^{\mathrm{k}} \mathrm{P}_{\mathrm{i}}}=\mathrm{P}_{1},
$$

де $\mathrm{P}_{1}$ - ймовірність стану, при якому система застосовується для контролю технічного стану апаратура радіонавігації (основний стан моделі експлуатації);

$\mathrm{P}_{\mathrm{i}}$ - ймовірність і-го стану системи із загальної кількості станів $\mathrm{k}, \mathrm{i}=\overline{1, \mathrm{k}}$.

Якщо стан апаратура радіонавігації визначається сукупністю $\mathrm{n}$ незалежних параметрів контролю $(v=\overline{1, n})$, то ймовірності цих станів описуються такими формулами:

$$
\begin{aligned}
& \mathrm{P}_{1,1}=\sum_{\ell=1}^{\mathrm{k}} \mathrm{P}_{\ell}^{\mathrm{c}}\left[\prod_{v=1}^{\mathrm{n}}\left(\mathrm{P}_{v}-\alpha_{v, \ell}\right)\right] ; \\
& \mathrm{P}_{1,2}=\sum_{\ell=1}^{\mathrm{k}} \mathrm{P}_{\ell}^{\mathrm{c}}\left[\begin{array}{c}
\prod_{v=1}^{\mathrm{n}} \mathrm{P}_{v}- \\
-\prod_{v=1}^{\mathrm{n}}\left(\mathrm{P}_{v}-\alpha_{v, \ell}\right)
\end{array}\right] \text {; } \\
& \mathrm{P}_{2,1}=\sum_{\ell=1}^{\mathrm{k}} \mathrm{P}_{\ell}^{\mathrm{c}}\left[\begin{array}{c}
\prod_{v=1}^{\mathrm{n}}\left(\mathrm{P}_{v}-\alpha_{v, \ell}+\beta_{v, \ell}\right)- \\
-\prod_{v=1}^{\mathrm{n}}\left(\mathrm{P}_{v}-\alpha_{v, \ell}\right)
\end{array}\right] \text {; } \\
& \mathrm{P}_{2,2}=\sum_{\ell=1}^{\mathrm{k}} \mathrm{P}_{1}^{\mathrm{c}}\left[\begin{array}{c}
1-\prod_{v=1}^{\mathrm{n}} \mathrm{P}_{v}-\prod_{v=1}^{\mathrm{n}}\left(\mathrm{P}_{v}-\alpha_{v, \ell}\right)- \\
-\prod_{v=1}^{\mathrm{n}}\left(\mathrm{P}_{v}-\alpha_{v, \ell}+\beta_{v, \ell}\right)
\end{array}\right] \text {, }
\end{aligned}
$$

де $\mathrm{P}_{v}$ - апріорна ймовірність знаходження $v$-го параметра контролю апаратури радіонавігації в області допустимих значень;

$\alpha_{v, l}, \beta_{v, l}-$ ймовірності помилок контролю І-го i II-го роду $v$-го параметра за умови, що мобільна контрольно-діагностична система знаходиться в стані $l$ відповідно.

Формули (2) є узагальненням формули (1) і тотожні при $v=1$.

Так як для мобільної контрольно-діагностичної системи за результатами іiі обслуговування розрізняють два стани:

$l=1$ - працездатна та допущена до обслуговування апаратури радіонавігації,

$l=2$ - мобільна контрольно-діагностична система непрацездатна та недопущена до обслуговування апаратури радіонавігації, 
то згідно формул (2) для визначення математичного сподівання перебування апаратури радіонавігації у відповідному стані є вірними формули, що мають такий вигляд:

$$
\begin{gathered}
\mathrm{m}_{1,1}= \\
=\mathrm{p}^{-}\left(\mathrm{m}^{\mathrm{M}}-\alpha_{1}\right)+\left(1-\mathrm{p}^{\mathrm{c}}\right)\left(\mathrm{P}^{\mathrm{O}}-\alpha_{2}\right) \\
\mathrm{m}_{1,2}=\mathrm{p}^{-} \alpha_{1}+\left(1-\mathrm{p}^{\mathrm{c}}\right) \alpha_{2} \\
\mathrm{~m}_{2,1}=\mathrm{p}^{-} \beta_{1}+\left(1-\mathrm{p}^{\mathrm{c}}\right) \beta_{2} \\
\mathrm{~m}_{2,2}= \\
=\mathrm{p}^{-}\left(1-\mathrm{P}^{\mathrm{O}}-\beta_{1}\right)+\left(1-\mathrm{p}^{\mathrm{c}}\right)\left(1-\mathrm{P}^{\mathrm{O}}-\beta_{2}\right)
\end{gathered}
$$

де $\mathrm{p}^{\mathrm{c}}$ - апріорна ймовірність знаходження мобільної контрольно-діагностичної системи у стані $l=1$;

$\alpha_{1}, \alpha_{2}$ - ймовірність помилок контролю апаратури радіонавігації І-го роду для $l=1$ і $l=2$ відповідно;

$\beta_{1}, \beta_{2}$ - ймовірність помилок контролю апаратури радіонавігації ІІ-го роду для $l=1$ і $l=2$ відповідно;

$\mathrm{P}^{\mathrm{O}}$ - апріорна ймовірність знаходження апаратури радіонавігації у працездатному стані.
Основною складністю при оцінці впливу якості обслуговування мобільної контрольно-діагностичної системи на готовність апаратури радіонавігації $€$ отримання аналітичних залежностей для $\alpha_{1}, \alpha_{2}$, $\beta_{1}, \beta_{2}$.

Так як для найбільш часто розповсюджених законів розподілу параметрів контролю та похибки вимірювання параметрів - нормального та рівномірного - неможливо отримати аналітичні вирази у загальному виді для функцій розподілу, запропоновано використання імітаційного моделювання.

Запропонована імітаційна модель основана на генерації нормальних розподілів дійсного значення $\mathrm{X}$ параметра контролю апаратури радіонавігації та похибки мобільної контрольно-діагностичної системи Y, що застосовується при контролі. Значення параметра контролю апаратури радіонавігації Z $€$ композицією розподілів X і Y, тобто

$$
\mathrm{Z}=\mathrm{X}+\mathrm{Y} \text {. }
$$

Значення параметрів з формул (3)

$$
\mathrm{p}^{\mathrm{c}}, \mathrm{P}^{\mathrm{O}}, \alpha_{1}, \alpha_{2}, \beta_{1}, \beta_{2}
$$

розраховуються як частоти потрапляння аргументів розподілів X, Y, Z у відповідних границях (табл. 1).

Таблица 1

Границі параметрів

\begin{tabular}{|c|c|c|c|}
\hline \multirow{2}{*}{$\begin{array}{c}\text { Параметри } \\
\text { формул (3) }\end{array}$} & $\begin{array}{c}\text { Працездатності } \\
\text { апаратури } \\
\text { радіонавігації }\end{array}$ & $\begin{array}{c}\text { Придатності } \\
\text { апаратури } \\
\text { радіонавігації }\end{array}$ & $\begin{array}{c}\text { Працездатності } \\
\text { мобільної контрольно- } \\
\text { діагностичної системи }\end{array}$ \\
\hline $\mathrm{p}^{\mathrm{c}}$ & - & - & $\mathrm{a}^{\prime}<\mathrm{y}<\mathrm{b}^{\prime}$ \\
\hline $\mathrm{P}^{\mathrm{O}}$ & $\mathrm{a}<\mathrm{X}<\mathrm{b}$ & - & $\mathrm{a}^{\prime}<\mathrm{Y}<\mathrm{b}^{\prime}$ \\
\hline$\alpha_{1}$ & $\mathrm{a}<\mathrm{X}<\mathrm{b}$ & $\mathrm{Z}<\mathrm{a}$ або $\mathrm{Z}>\mathrm{b}$ & $\mathrm{Y}<\mathrm{a}^{\prime}$ або $\mathrm{Y}>\mathrm{b}^{\prime}$ \\
\hline$\alpha_{2}$ & $\mathrm{a}<\mathrm{X}<\mathrm{b}$ & $\mathrm{Z}<\mathrm{a}$ або $\mathrm{Z}>\mathrm{b}$ & $\mathrm{a}^{\prime}<\mathrm{Y}<\mathrm{b}^{\prime}$ \\
\hline$\beta_{1}$ & $\mathrm{X}<\mathrm{a}$ або $\mathrm{X}>\mathrm{b}$ & $\mathrm{a}<\mathrm{Z}<\mathrm{b}$ & $\mathrm{Y}<\mathrm{a}^{\prime}$ або $\mathrm{Y}>\mathrm{b}^{\prime}$ \\
\hline$\beta_{2}$ & $\mathrm{X}<\mathrm{a}$ або $\mathrm{X}>\mathrm{b}$ & $\mathrm{a}<\mathrm{Z}<\mathrm{b}$ & \multicolumn{2}{|c|}{} \\
\hline
\end{tabular}

У табл. 1 введені такі позначення:

$\mathrm{a}, \mathrm{b}$ - нижня та верхня границя області допустимих значень параметра контролю апаратури радіонавігації відповідно;

$a^{\prime}, b^{\prime}$ - нижня та верхня границі області допустимих значень похибки мобільної контрольнодіагностичної системи відповідно.

У результаті використання розробленої імітаційної моделі та розрахунку формул (3) установле- но, що похибки, у бік заниження, в оцінці працездатного стану мобільної контрольно-діагностичної системи, яка застосовується при контролю технічного стану апаратури радіонавігації на $(1,5-2) \%$, що виникають у результаті математичного моделювання процесів їх обслуговування, для найбільш типових значень:

$$
\mathrm{P}^{\mathrm{O}}=0,95 ; \mathrm{p}^{\mathrm{c}}=0,95
$$




$$
\begin{gathered}
\alpha_{1}=0,01 ; \alpha_{2}=0,01 ; \\
\beta_{1}=0,01 ; \beta_{2}=0,01
\end{gathered}
$$

надають похибку оцінки коефіцієнта готовності о мобільної контрольно-діагностичної системи порядку десятих процента.

Відповідно до отриманих результатів можна зробити висновок про актуальність задачі підвищення точності моделювання процесів обслуговування мобільної контрольно-діагностичної системи, що застосовується при контролі технічного стану апаратури радіонавігації морського транспорту.

Так розрахунки показали, що підвищення коефіцієнту готовності мобільної контрольно-діагностичної системи на $(1,5$ - 2) \% дозволяють підвищити достовірність контролю апаратури радіонавігації на $(2-10) \%$.

\section{Висновки}

Розроблена імітаційна модель впливу точності оцінки коефіцієнту готовності мобільних контрольно-діагностичних систем на достовірність контролю апаратури радіонавігації морського транспорту дозволяє визначити взаємозв'язок між якість обслуговування системи та достовірністю визначення реального технічного стану апаратури , що контролюється.

Наступні публікації будуть направлені на розробку математичної моделі «зразок (система), що контролюється - засіб контролю» і оцінку показників ефективності експлуатації радіотехнічних засобів морського транспорту за допомогою такої моделі.

\section{Список літератури}

1. Лукьянович Н.В. Морской транспорт в мировой экономике / Н.В. Лукьянович. - М.: Моркнига, 2009. $162 \mathrm{c.}$

2. Морская радиоэлектроника / Соловьев И.В. и др.; под ред. Кравченко В.А. - СПб.: Политехника, 2003. $185 \mathrm{c}$.

3. Дорогунцов С. Морський транспорт; Розміщення трудових сил України / С. Дорогунцов // Подія. - 2011. № 3. - C. 22-25.

4. Барзилович Е.Ю. Модели технического обслуживания сложных систем / Е.Ю. Барзилович. - М.: Высшая школа, 1982. - $231 \mathrm{c}$.

5. Основы эксплуатации средств измерений / В.А. Кузнечов, А.Н. Пашков, О.А. Подольский и др.; под ред. Р.П. Покровского. - М.: Радио и связь, 1984. - 184 c.

6. K вопросу построения автоматизированной системы мониторинга параметров высокоточного навигаиионного поля / В.В. Каретников, И.В. Пащенко, А.И. Соколов, И.Г. Кузнечов // Морская радиоэлектроника. 2015. - № 2 (52). - C. 24-27.

7. Герасимов С.В. Техніко-економічне обтрунтування розробки (модернізачії, закупівлі) складних технічних комплексів / С.В. Герасимов, А.М. Клименко, Т.А. Пінчук // Збірник наукових праџь Харківського університету Повітряних Сил. - Х.: ХУПС. - 2010. - Вип. 1 (23). C. $111-115$.

8. Демидов Б.О. Розробка військово-економічного показника ефективності експлуатації перспективноі пересувної лабораторії вимірювальної техніки / Б.О. Демидов, М.В. Борисенко, С.В. Герасимов // Збірник наукових праць Харківського університету Повітряних Сил. - Х.: ХУПС. - 2014. - Bun. 3 (40). - C. 11-16.

Надійшла до редколегії 21.12.2017

Рецензент: д-р техн. наук, доц. М.А. Павленко, Харківський національний університет Повітряних Сил імені Івана Кожедуба, Харків.

\title{
ИМИТАЦИОННАЯ МОДЕЛЬ ВЛИЯНИЯ ТОЧНОСТИ ОЦЕНКИ КОЭФФИЦИЕНТА ГОТОВНОСТИ МОБИЛЬНЫХ КОНТРОЛЬНО-ДИАГНОСТИЧЕСКИХ СИСТЕМ НА ДОСТОВЕРНОСТЬ КОНТРОЛЯ АППАРАТУРЫ РАДИОНАВИГАЦИИ МОРСКОГО ТРАНСПОРТА
}

\author{
П.Г. Бердник, Ю.Е. Шапран
}

В статье показано влияние технического состояния аппаратуры радионавигации морского транспорта на временные и экономические показатели морских перевозок. Предложенный метод построения имитационной модели, который заключается в учете вероятностей нахождения мобильных контрольно-диагностических систем и аппаратуры радионавигации в соответствующих состояниях эксплуатации - исправном или неисправном. Разработаны аналитические соотношения для определения вероятности нахождения аппаратуры радионавигации в соответствующих состояниях эксплуатации. Предложена имитационная модель, основанная на особенностях параметров контроля аппаратуры радионавигаџии и ошибок мобильной контрольно-диагностической системы, применяемой при контроле.

Ключевые слова: имитационная модель, контроль, техническое состояние, аппаратура радионавигации, морской транспорт.

\section{IMITATION MODEL OF INFLUENCE OF ACCURACY OF ACCURACY OF THE COEFFICIENT OF THE READINESS OF MOBILE CONTROL AND DIAGNOSTIC SYSTEMS ON THE ACCURACY OF CONTROL OF THE TRANSPORT SEA RADIONAVIGATION APPARATUS}

\author{
P.G. Berdnik, Yu.Ye. Shapran
}

The article shows the influence of the technical state of the radio navigation equipment of transport sea on the temporary and economic indicators of sea transport. The proposed method for constructing an imitation model, which consists in taking into account the probabilities of finding mobile diagnostic and control systems and radio navigation equipment in the corresponding operating states - serviceable or faulty. Analytical relations have been developed to determine the probability of finding radio navigation equipment in the corresponding operating states. A simulation model based on the features of the monitoring parameters of the radio navigation equipment and the errors of the mobile control and diagnostic system used in the control is proposed.

Keywords: simulation model, control, technical condition, radio navigation equipment, transport sea. 